\title{
The Biogeography of Invasive Plants - Projecting Range Shifts with Climate Change
}

\author{
Bethany A. Bradley \\ Environmental Conservation, University of Massachusetts, \\ Amherst, Massachusetts, USA
}

\begin{abstract}
Correlative models between species occurrences and climate (here referred to as 'habitat suitability models') have become increasingly popular for forecasting risk from invasive plants under current and future climate scenarios. These models have the potential to inform management and monitoring efforts by prioritizing landscapes considered at highest risk under a changing climate. However, a wide range of choices regarding climatic predictor variables, modelling approaches and even distributional data sets influences the resulting projections. The effects of these choices are seldom defined explicitly, which reduces their utility for scientists and managers alike. This chapter reviews common practices of habitat suitability modelling as they apply to invasive plants. The chapter also reviews major findings of recent projections of range shifts in invasive plants. In both cases, the aim is to explore how different choices of predictors, models and input data can influence conclusions in a habitat suitability modelling framework and develop recommendations for best practices.
\end{abstract}

\section{Introduction}

Identifying and eradicating early infestations is the most effective strategy for preventing invasions (Moody and Mack, 1988; Strayer, 2009). Projections of potential range shifts with climate change could provide a valuable tool for informing ecosystem monitoring and targeting high-risk species (Stohlgren and Schnase, 2006). In response to this need, spatial models of species habitat under current and future climate conditions have become increasingly prevalent in recent years, with many investigators focusing on invasive plants.

Conceptually, the approach is relatively straightforward. Habitat suitability modelling uses empirical relationships between species occurrence and environmental variables (e.g. climate, topography, land use) to define habitat spatially across landscapes or regions (Fig. 15.1). Typically, this process involves collecting locations where an invasive plant is present along with spatial maps or models of the environmental conditions (Fig. 15.1a). Next, presence locations are used to specify environmental conditions in which the invasive plant can establish successfully, defining its potential habitat in environmental space (Fig. 15.1b). Finally, environmental habitat is projected back on to geographic space to determine the areas where the species could potentially establish (Fig. 15.1c). For invasive species, the potential range usually includes substantial land area that has not yet been invaded.

There are numerous synonymous or nearsynonymous terms used to describe this 
(a)

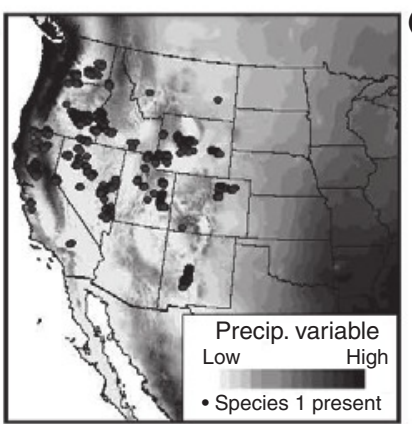

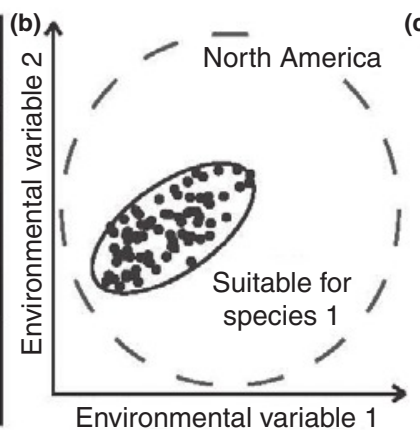

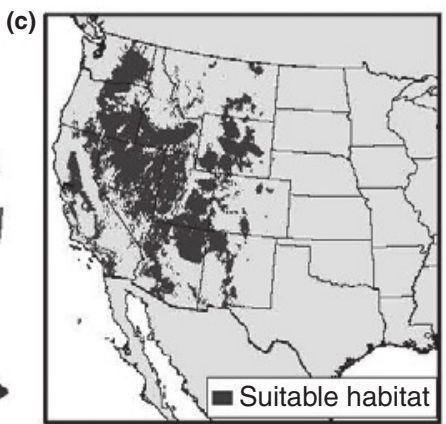

Fig. 15.1. Schematic representation of habitat suitability modelling. (a) Geographic occurrences of an invasive species are compared to climatic variables to calculate (b) climatic suitability for that species. (c) Climatic suitability is mapped back on to geographic space to create a model of suitable habitat, or potential invasive species range.

modelling process (Franklin, 2009). This chapter refers to it as 'habitat suitability modelling'. Other common terms include 'species distribution modelling', 'ecological niche modelling' and 'bioclimatic envelope modelling'. All of these models aim to predict the potential distribution of species, although the latter term typically implies that the environmental predictor variables are related to climate only.

Habitat suitability models (HSMs) do not contain any physiological information about invasive plant species, nor do they include any mechanistic information about spread or competition. They are purely empirical. As a result, they have been criticized, because correlation between climate and distribution does not necessarily imply a causal relationship between climate and distribution (Dormann, 2007). Environmental variables often have a high degree of correlation - for example, locations that have high annual precipitation also tend to be wet in the summer. So, the environmental variables that are empirically the best predictors of species distribution may not actually be the ones influencing plant growth. For a hypothetical plant, annual precipitation might provide the best fit empirically, even though summer precipitation actually affects how quickly the plant can grow and how extensive the invasion could ultimately be.

\section{Model Limitations}

How important is climate for modelling plant invasion risk? At a regional scale, climate can limit plant growth and competitive ability, defining broad boundaries on where species can establish, persist and potentially become problematic. However, at landscape and local scales, which are much more management relevant, other environmental conditions such as topography, soils and disturbance may be far more important (Pearson and Dawson, 2003). Moreover, the locations of initial introduction and dispersal ability influence how quickly non-native species are able to become an important component of regional flora (Stohlgren et al., 2011; Stohlgren et al., Part II, Chapter 10, this volume). All of these components play important roles in understanding invasion risk. Here, the focus is only on the approaches to modelling regional invasion risk in response to climate and climate change.

\section{Predictor Variables}

Under current climate conditions, switching one climatic predictor for another correlated predictor will have little effect on the overall projection. Studies have shown that empirical models based on current climate 
have similar levels of accuracy to mechanistic models (Hijmans and Graham, 2006; Estes et al., 2013). However, there is no way to measure accuracy under future climate conditions. And, if physiologically important variables are neglected in HSMs in favour of correlated but physiologically unimportant variables, this choice could have dramatic effects on projections of future range under climate change. To follow our hypothetical example above, if our plant's growth is influenced primarily by summer precipitation, then a model of future habitat based on annual average precipitation could skew projections of range shifts with climate change. Skewed projections are particularly likely if seasonal climate predictors respond differently; for example, if summer precipitation decreases but annual precipitation remains the same.

The best way to work around this problem is to select climatic predictor variables that are known to be physiologically important to the target species. This information can sometimes be found from experimental and observational data. In the absence of physiological information, climatic variables that provide the best empirical fit can be compared to expert knowledge of the species or ecosystem in order to select appropriate predictors (Bradley et al., 2010a). In all cases, models of current and future distribution should be treated as hypotheses (due not only to climatic predictor uncertainty but also to uncertainty in climate projections and changes to species-environment interactions). If the climatic predictors are later found to represent physiology poorly, then any projections of future habitat should be treated with caution.

\section{Invasive Species Equilibrium}

One underlying assumption of HSMs is that the target species is at equilibrium (or near equilibrium) with current environmental conditions (Guisan and Zimmermann, 2000). If a species is not in equilibrium, then distribution points will be missing from locations where climate is actually suitable (where the species could establish if it were introduced) and spatial models will underpredict potential establishment. Invasive species, by definition, are not at equilibrium (Václavík and Meentemeyer, 2012). Their continued spread through landscapes and regions fails the equilibrium assumption.

However, for the purposes of modelling, equilibrium does not require that the species occur everywhere that it could potentially establish geographically. Rather, equilibrium requires that the species encompass the environmental space where it could potentially establish. Environmental equilibrium is achieved much earlier than geographic equilibrium. For example, Welk (2004) showed that predictions of HSMs for purple loosestrife (Lythrum salicaria) invasion in North America stopped changing after distribution points from the first 120150 years of invasion were added. Occurrence points from the past 50 years of invasion did not change the overall prediction, even though they doubled the available data. Thus, it is a reasonable assumption that long-established and/or widely introduced invasive species approximate climatic equilibrium and are appropriate for use in habitat suitability modelling. If a species is in the early stages of invasion and distribution points are only available in a localized area, then it is safe to assume that habitat models will underestimate its potential range vastly. The amount of time that it takes a species to approximate climatic equilibrium likely varies with the introduction and dispersal mechanism. For example, plants introduced as ornamentals may be widely distributed early on and approximate equilibrium sooner.

\section{Modelling Considerations}

\section{Choice of model}

A variety of different methodological approaches have been applied to habitat suitability modelling. These methods can be broken down roughly into presence/absence, presence/pseudo-absence and presence-only models. Presence/absence models require distribution not only for the location of 
species presence but also for locations of species absence. Absence data for invasive plants can be problematic, because of the previously mentioned concerns with equilibrium. An absence might mean that the species cannot establish at that location. But, it could also mean that the species can establish, but has not yet been introduced. As a result, presence/absence models are typically used only at landscape or local scales to ask questions such as how local disturbance influences invasion (e.g. Bradley and Mustard, 2006). At regional scales, the likelihood of a 'false' absence skewing model results is much greater and there are few data sets that include both presence and absence. Hence, presence/absence models are rarely used to predict climatic suitability or to forecast species range shifts in response to climate change.

Presence/pseudo-absence models use species occurrences and a set of pseudoabsence points chosen at random from the available environmental space, or 'background'. Suitable climate conditions are identified by comparing the occurrences to the available climate conditions. If more occurrence points are found than expected relative to the available climate space, then those climate conditions are considered more suitable for invasive plant establishment. Many examples of presence/pseudoabsence models have been developed (Elith et al., 2006), but the most widely used approach currently is based on a maximum entropy (or MaxEnt) approach developed by Phillips et al. (2006).

There has been considerable debate within the modelling community on how to define 'background' from which to sample pseudo-absence points (VanDerWal et al., 2009a; Lobo et al., 2010; Acevedo et al., 2012). If defined too broadly, the model for current climate conditions might be very precise, but the predictor variables and probability relationships will be minimally informative. For example, a broad background of North America relative to an invasion in the Sonoran Desert is more likely to describe the unique climatic conditions of that desert (relative to North America) rather than the species itself. Too broad a background will underpredict future range with climate change and may bias the climatic predictor variables if they are not defined physiologically (Acevedo et al., 2012). If defined too narrowly, pseudoabsence points are more likely to be placed in locations that are actually climatically suitable, thereby biasing the projection. To date, there is no standard approach for defining background in order to minimize bias in presence/pseudo-absence models. For invasive plants, which are not in equilibrium geographically, the likelihood of creating biased models when selecting pseudo-absence points is high (Lobo et al., 2010).

Presence-only models do not assume any information about absence locations or background environmental space (see Tsoar et al., 2007, for examples). One example of a presence-only model is Mahalanobis Distance, which is a multivariate technique that defines perpendicular major and minor axes within the data and calculates distance from the data centroid relative to the covariance of axes lengths (Farber and Kadmon, 2003). This model measures only distance from the presence data; absences are unnecessary. Presence-only models will almost always predict a larger area of suitable habitat than presence/pseudoabsence models, because they have no direct mechanism for excluding some subsets of environmental space. Jiménez-Valverde et al. (2008) note that this larger predicted area has often been interpreted as an indication of overprediction, and therefore poor model performance. However, accuracy assessments are all performed relative to current species distribution, and may be unreliable measures of the accuracy of potential future range. It is equally probable that presence/pseudo-absence models underpredict future range due to biased definition of the background extents (JiménezValverde et al., 2008). A presence-only approach to modelling future habitat suitability under climate change is the least likely to underpredict potential range or be biased in unknown ways.

Although presence-only models are less prone to underprediction (false negatives), 
presence/pseudo-absence models may be less prone to overprediction (false positives). A balance between minimizing both of these errors may ultimately be most useful for guiding regional monitoring and management. Hence, an ensemble approach (Araujo and New, 2007) that combines the projections of multiple models and climate projections could identify priority management areas.

\section{No-analogue climate}

The Earth's surface is not currently experiencing all the possible combinations of climate conditions that could exist. In some locations, rising temperatures and altered precipitation will change local climate to conditions that historically have not been experienced. These 'no-analogue' climate conditions (Williams and Jackson, 2007) may pose a problem for habitat modelling. It is possible to imagine climate conditions that do not currently exist on Earth, but in which a plant could still establish. Maybe the conditions are slightly warmer than current temperatures, or maybe they reflect an annual monsoon arriving a month later. In either case, our lack of invasive plant establishment data does not signify that the species cannot tolerate the environmental conditions, just that the location does not exist.

When projecting into these no-analogue climate conditions, models must extrapolate beyond the available data. The more complex the model, the greater the chances it will produce a problematic relationship beyond the current environmental conditions on which the model is trained. This problem is more likely in presence/absence or presence/ pseudo-absence models, and provides further rationale for including presenceonly models when modelling range shifts with climate change. Some presence/ pseudo-absence models have developed methods for dealing with no-analogue conditions. For example, 'clamping' in MaxEnt (Phillips et al., 2006) sets the value of any location outside the training range as equal to the edge of the training range. However, as a general rule, there is much higher uncertainty in projecting range shifts into climate conditions with no current analogue (Elith et al., 2010). Identifying and highlighting no-analogue climate conditions (Williams and Jackson, 2007) within habitat projections would help to convey uncertainty in risk assessments.

\section{Range shifts with climate change}

Although rising levels of $\mathrm{CO}_{2}$ increase the growth of invasive plants relative to native plants (Blumenthal and Kray, Part I, Chapter 5 , this volume), higher temperatures and altered precipitation do not necessarily provide a similar advantage. At the cold edge of invasive plant ranges, warming temperatures might enable plants to expand. For example, kudzu's (Pueraria lobata) range is likely limited at its northern edge in the USA by its intolerance of frost. With higher temperatures, this range margin is likely to move northwards (Bradley et al., 2010b). However, at the warm edge, higher temperatures could increase evapotranspiration and reduce invasive plant competitiveness. Observations of native species have shown a consistent shift in species distribution towards the colder edge and away from the warmer edge with warming temperatures (Parmesan and Yohe, 2003; Root et al., 2003). Similar range shifts are likely for invasive plants (Bradley et al., 2009).

A number of projections of invasive plant range shifts with climate change have shown that both expanded and contracted range is likely (Fig. 15.2). In North America, of five problematic invasive plants, two showed primarily range expansion, two showed primarily range contraction and one showed roughly equal expansion and contraction (Bradley et al., 2009). In South Africa, 30 grass species showed primarily contraction of potential range due to climate warming, with up to $50 \%$ loss of potential range by mid-century (Parker-Allie et al., 2009). In Australia, three hawkweed species showed a loss of potential range of $20 \%$ by 2030 (Beaumont et al., 2009). In North America, projections of range shifts by 2035 for 12 


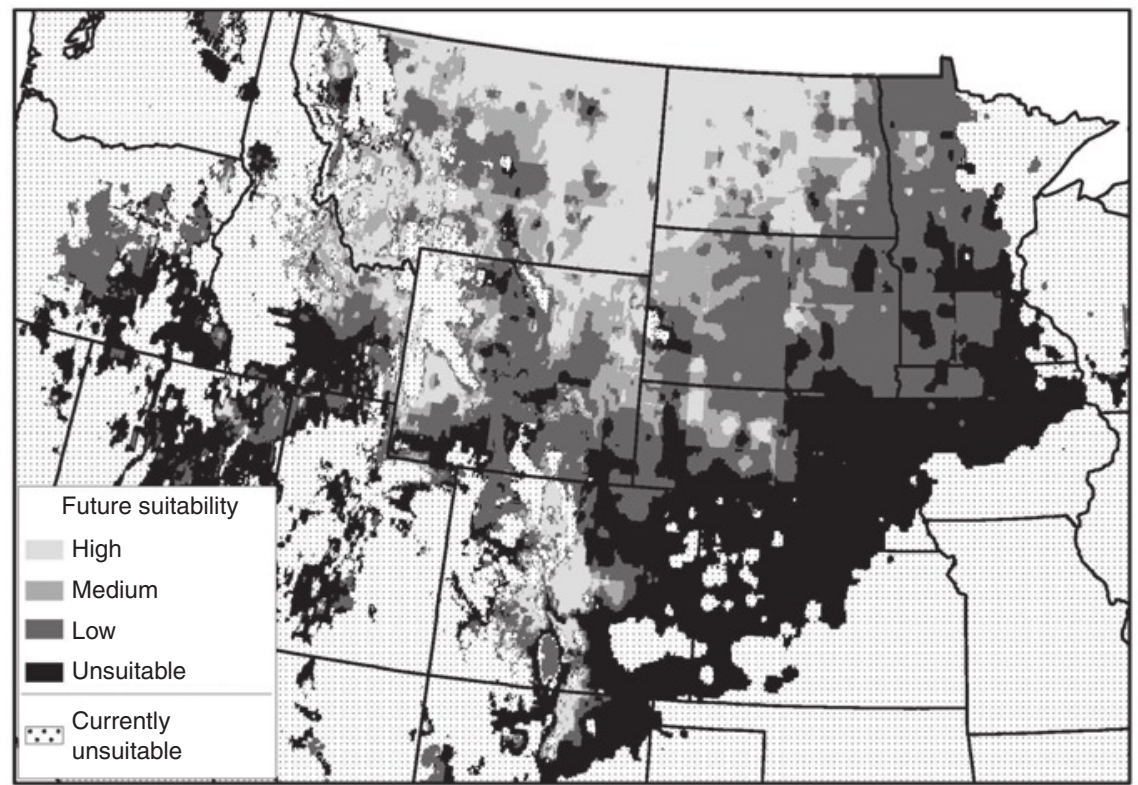

Fig. 15.2. Future climate conditions are likely to lead to substantial habitat loss for leafy spurge (Euphorbia esula) in the USA by the end of the century (adapted from Bradley et al., 2009). Black areas on the map are currently climatically suitable, but lose suitability under climate change.

grasses and forbs showed more contraction of potential land area than expansion (Holcombe et al., 2010). In Australia, models for 72 weeds of national significance projected that range will contract for the vast majority of species, with losses averaging $40 \%$ of potential range by midcentury (O'Donnell et al., 2012). Losses of potential range suggest that establishment of these species might not be quite so widespread in the future.

These studies have focused primarily on shifts in potential range. However, loss of habitat within the currently invaded range is also likely. For example, of the three species with reduced potential range in North America, $30 \%$ of currently invaded areas were likely to become climatically unsuitable by the end of the century (Bradley et al., 2009). This loss of habitat suggests that climate change may cause some invasive plants to become less competitive in, or even retreat from, areas that they have already invaded. Invasive species retreat highlights the intriguing possibility of widespread restoration opportunities due to climate change (Bradley et al., 2009). However, the term 'restoration' is poor for this type of opportunity, because altered climate conditions make it counterproductive to restore the native vegetation that existed prior to invasion. Rather, a type of transformative restoration may be needed to revegetate landscapes with non-invasive, regionally native species that can survive the novel climate conditions and will serve the desired function of the ecosystem (e.g. soil stability, carbon storage, animal habitat) (Bradley and Wilcove, 2009). The development of ecological goals and acceptable risks for assisted migration are needed if these opportunities are to be realized (Harris et al., 2006; McLachlan et al., 2007; Richardson et al., 2009).

Although a number of studies now suggest that range contractions will be just as important, if not more so, than range expansion for invasive plants, the total sample size still remains small. There are thousands of non-native species that have 
become invasive, but the potential ranges of only a handful have been modelled. For the majority of invasive plants that have not been modelled, potential range shifts are likely to mimic those observed in native species. Warmer temperatures are causing an upward elevational and a poleward directional shift in distributions, and a similar response is likely for invasive plants. For regional managers attempting to catalogue future risk, species that have invaded neighbouring regions with slightly warmer climates likely pose the greatest risk under climate change.

\section{Vulnerable ecosystems}

The pool of invasive species with climate change projections is small relative to all global invaders and tends to be focused on the most problematic examples. This small sample size limits the potential for identifying regions or biomes that might be more susceptible under future climate conditions. To date, only one study in Australia has attempted to assess whether some biomes have higher risk than others. O'Donnell et al. (2012) modelled 72 weeds of national significance in Australia under current and future climate conditions. They projected two main invasion 'hotspots', one in the south-east and one in the south-west part of the country. Both hotspots were primarily temperate ecosystems. However, this finding might reflect the unique geography of Australia rather than temperate ecosystems as higher risk. Temperate ecosystems are the poleward destination of all tropical invasive plants in Australia, and the country's central desert reduces the available range. Interestingly, the authors note that the invasion hotspots also occur in areas with intensive land use, so disturbance is likely to create more opportunities for the establishment of novel species in these particular areas.

Identifying the most vulnerable ecoregions in the near term may be linked more closely to trade, particularly imports and the availability of ornamental plants, than to climatic suitability. The horticulture industry is the primary source of non-native plant introductions (Reichard and White, 2001; Mack and Erneberg, 2002), and trade is on the rise (Hulme, 2009; Bradley et al., 2012). Ecoregions with higher rates of trade (Vila and Pujadas, 2001) and/or wider distribution of aliens versus natives (Stohlgren et al., 2011) ultimately may see the most dramatic shifts in invasive species in response to climate change.

\section{Invasion Risk: Establishment Versus Impact}

Invasive plants are unique in that they have multiple different ranges: the range in which they are native and all of the locations where they have been introduced and successfully established. Often, the native range and the invaded ranges encompass different climatic space (Broennimann et al., 2007), which greatly expands the potential geographic locations of invasive species establishment. Models based on the invaded range alone are likely to underestimate the potential for establishment, and therefore underestimate the potential range under climate change.

However, using all possible distribution data in a suitability model assumes that establishment is the most important stage of invasion risk to predict. For native species, trying to figure out where a plant could establish and persist under climate change is important for informing conservation (Thomas et al., 2004; Kremen et al., 2008), restoration and even assisted migration (Richardson et al., 2009). But, for invasive species, the management applications of understanding potential establishment are much less direct. Many invasive plants have wide climatic tolerances (Pysek and Richardson, 2007), and could establish under a variety of conditions. For example, cheatgrass (Bromus tectorum) is established in all 50 states and most Canadian provinces (Fig. 15.3) (USDA-NRCS, 2012). But, it is abundant and has a high impact only in western states, where its early season growth helps it outcompete native species for limited water resources (Mack, 1981; Knapp, 1996) and where its fine fuel biomass 


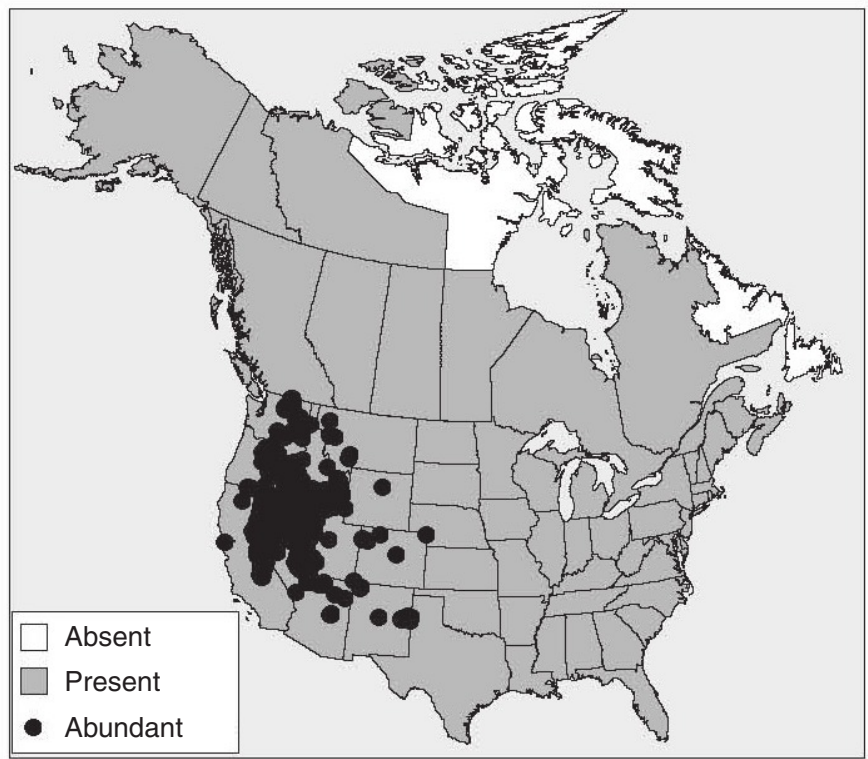

Fig. 15.3. Comparison of establishment range to abundance/impact range for cheatgrass (Bromus tectorum) in North America. State-/province-level establishment information is available on the USDA PLANTS website (USDA-NRCS, 2012). Point locations of high abundance come from USGS GAP analysis data for the north-west and south-west and from California.

increases fire frequency (D’Antonio and Vitousek, 1992; Brooks et al., 2004; Balch et al., 2013) (Fig. 15.3). These types of impacts are not a concern in eastern states, even though the species is well established.

The climatic and geographical space where an invasive species has an impact is a smaller subset of its total establishment. This space has been termed 'damage niche' (McDonald et al., 2009; DiTommaso et al., Part III, Chapter 16, this volume) or 'impact niche' (Bradley, 2013). Modelling the current and future geographical extents of the impact niche is much more management relevant than establishment or range alone (Hulme, 2006; McDonald et al., 2009). Yet, the two invasion stages of establishment and impact (Lockwood et al., 2007) are often confusingly lumped together in model projections under the single term 'invasion risk'.

If the goal of a model is to identify the current and potential range of species establishment, then all available distribution data should be used (including data from the native range and any other invaded ranges).
Not using all available establishment data will result in an underestimate of potential establishment. But, what if the goal is a more management-relevant assessment of the current and future geographical extents of impact? The choice of distribution data in this case is not straightforward. Very few distribution data sets contain any sort of measure of impact, particularly because impact itself is notoriously difficult to quantify, changes through time as species interact and could be measured for a range of different native competitors and/or ecosystem processes. An easier-to-measure proxy for impact in the case of invasive plants is abundance. Some plant species have meaningful impacts at low abundance, but high abundance always leads to greater impacts (Parker et al., 1999). Unfortunately, even abundance or cover is rarely available in distribution data sets, particularly at the coarse $(>1 \mathrm{~km})$ spatial resolutions typically used to model climatic habitat.

One thing is clear, distribution data, even if limited to the invaded range, are a poor 
proxy for impact. As a result, models of suitability based on distribution data will overestimate impact (Bradley, 2013). This is partially due to the establishment niche being much larger than the impact niche. But, this phenomenon is also a function of invasive plant distribution data sets themselves. Herbarium collections, often available online from sources such as the Global Biodiversity Information Facility (http://www.gbif.org/), tend to be focused on collecting individuals where the species is rare. Hence, invasive plant herbarium records are more likely to be located in sites with low abundance, and therefore low impact. Indeed, herbarium records for problematic invasive plants in the western USA were located in regions where managers considered the species to be absent nearly $60 \%$ of the time (Bradley, 2013).

Invasive plant distribution data sets collected by managers and compiled regionally, such as the Early Detection and Distribution Mapping System (http:// EDDMaps.org/; Wallace and Bargeron, Part III, Chapter 13, this volume) or the invasive plant atlas of New England (http://www. eddmaps.org/ipane/), tend to be focused on early detection and rapid response. Because control is more effective for early infestations (Moody and Mack, 1988), treatment tends to be focused on areas with low abundance. Hence, distribution data compiled regionally also tend to be skewed towards low abundance (Marvin et al., 2009; Bradley, 2013). As a result, distribution data available in the invaded range are likely to be a poor proxy for the geographic and climatic conditions that define the impact or damage niche.

\section{Establishment Models Do Not Predict Impact}

HSMs create a surface of suitability values that are related to the probability that a species could establish at a given location (Fig. 15.4a). MaxEnt, for example, produces a 'gain' value ranging from zero to one, where high numbers indicate higher probability of establishment. It seems intuitive that higher probability of establishment should also be related to higher abundance, and therefore impact. If true, distribution data alone could be used to (a)

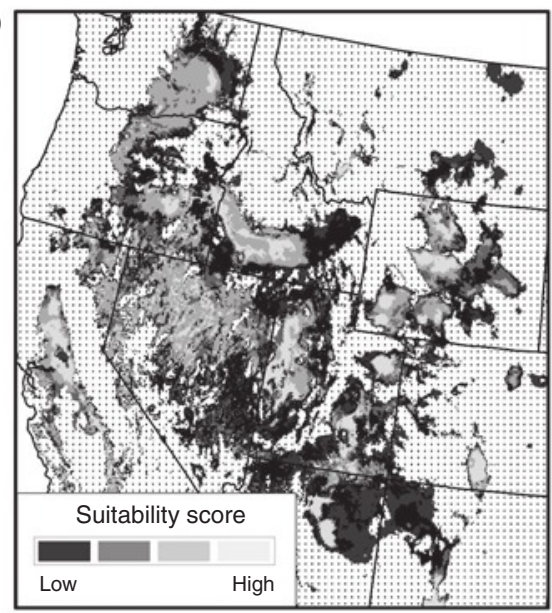

(b)

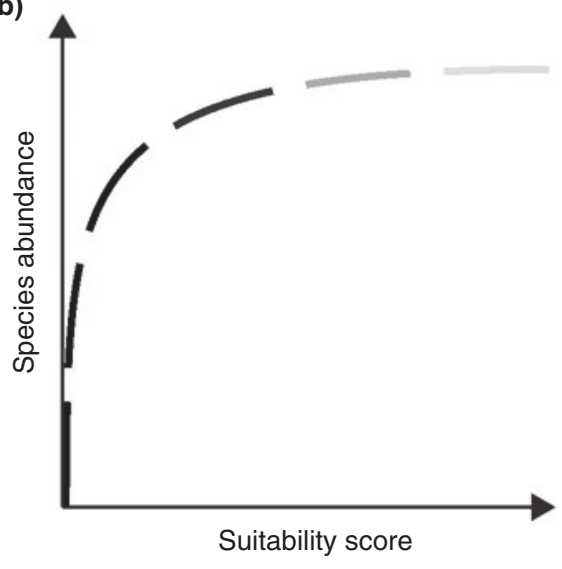

Fig. 15.4. Habitat suitability scores based on distribution data are linked poorly to abundance. (a) Probability of establishment for an invasive plant in the western USA based on MaxEnt gain values (Phillips et al., 2006). White is unsuitable, lighter shades have higher suitability. (b) Typical relationship between suitability scores and species abundance. 
predict impact by identifying locations with the highest suitability for establishment.

Relationships between modelled suitability based on distribution data and abundance have been tested for a number of species, including birds (VanDerWal et al., 2009b), mammals (Tôrres et al., 2012), arthropods (Jiménez-Valverde et al., 2009) and plants (Pearce and Ferrier, 2001; Nielsen et al., 2005; Estes et al., 2013). Rather than finding a strong relationship between suitability for establishment and measured abundance, these studies have found low or insignificant correlations. In several cases, the relationship is represented best as a step function, where low suitability corresponds to absence but high suitability corresponds to any value of abundance from low to high (Fig. 15.4b).

\section{How Can We Predict Impact?}

If distribution data are a poor proxy for impact niche, and suitability for establishment is a poor predictor of impact, is there any way to predict impact niche under current and future climate conditions? One positive finding is that models appear to be able to predict abundance (a proxy for impact) using continuous abundance data. Kulhanek et al. (2011) showed that observed abundance of invasive carp in Minnesota lakes (USA) could be used to predict the abundance of carp in South Dakota lakes. Unfortunately, continuous abundance data are extremely rare, particularly at the regional scales needed to link abundance to climate. A few regional abundance data sets have been collected in the USA, including the forest inventory and analysis (FIA) data set (http://www.fia.fs.fed.us/) used by the US Forest Service to inventory forest resources and the national gap analysis program (GAP) data sets used to validate state and regional land cover classifications. However, these data are focused on native species and are likely to overlook all but the most problematic invasive plants.

One innovative approach to modelling the impact or damage niche is to create a subset of distribution data based on locations known to have a high impact. McDonald et al. (2009) modelled current and future potential damage to crop species by identifying the states with high economic losses to two invasive species (Bridges, 1992), velvetleaf (Abutilon theophrasti) and Johnsongrass (Sorghum halepense), and using those state locations as distribution data for suitability models. This approach could be applied more widely to invasive plants based on expert knowledge of where the species has the highest impact, with the results less likely to overestimate impact than distribution data alone.

Finally, although suitability models based on distribution data are correlated poorly to abundance (Fig. 15.3), a recent study suggests that suitability models based on high-abundance locations are well correlated with abundance. Estes et al. (2013) showed that suitability values derived from a MaxEnt (Phillips et al., 2006) model based on locations of high-yield maize in South Africa were correlated linearly $\left(R^{2}=0.6\right)$ to continuous measurements of maize yield. This finding suggests that models based on point locations of known high abundance, such as the ones created by McDonald et al. (2009), could do better than just modelling impact/non-impact by predicting levels of potential abundance. The study is based on a single plant species and needs wider testing, but the approach of modelling damage or impact niche is very promising for invasive plant risk assessments.

\section{Conclusions}

Although habitat suitability modelling is conceptually straightforward, the case of forecasting plant invasions due to climate change presents a unique set of challenges. While models of establishment risk under current climate are likely robust, choices of modelling approach, distribution data and climatic predictors can have substantial effects on projections of range shifts with climate change. The limitations and likely biases of model and data choices are communicated poorly to managers, and better efforts towards transparency are needed. 
The sample size of predictive models for invasive plants remains small relative to the total pool of global invaders. However, models have consistently shown both potential for expansion and likely contraction of invasive plant range. It is currently unknown whether the impact niche is projected to follow similar expansion and contraction patterns as the total range. Likely invasive plant expansion suggests that managers should be including new species in monitoring efforts, particularly the problematic species from warmerclimate neighbours. Invasive plant contraction due to climate change may open a window of unique opportunity for the targeted restoration of high-priority invaded ecosystems.

\section{References}

Acevedo, P., Jiménez-Valverde, A., Lobo, J.M. and Real, R. (2012) Delimiting the geographical background in species distribution modelling. Journal of Biogeography 39, 1383-1390.

Araujo, M.B. and New, M. (2007) Ensemble forecasting of species distributions. Trends in Ecology and Evolution 22, 42-47.

Balch, J.K., Bradley, B.A., D'Antonio, C.M. and Gomez-Dans, J. (2013) Introduced annual grass increases regional fire activity across the arid western USA (1980-2009). Global Change Biology 19, 173-183.

Beaumont, L.J., Gallagher, R.V., Downey, P.O., Thuiller, W., Leishman, M.R. and Hughes, L. (2009) Modelling the impact of Hieracium spp. on protected areas in Australia under future climates. Ecography 32, 757-764.

Bradley, B.A. (2013) Distribution models of invasive plants over-estimate potential impact. Biological Invasions 15, 1417-1429.

Bradley, B.A. and Mustard, J.F. (2006) Characterizing the landscape dynamics of an invasive plant and risk of invasion using remote sensing. Ecological Applications 16, 1132-1147.

Bradley, B.A. and Wilcove, D.S. (2009) When invasive plants disappear: transformative restoration possibilities in the western United States resulting from climate change. Restoration Ecology 17, 715-721.

Bradley, B.A., Oppenheimer, M. and Wilcove, D.S. (2009) Climate change and plant invasion: restoration opportunities ahead? Global Change Biology 15, 1511-1521.
Bradley, B.A., Blumenthal, D.M., Wilcove, D.S. and Ziska, L.H. (2010a) Predicting plant invasions in an era of global change. Trends in Ecology and Evolution 25, 310-318.

Bradley, B.A., Wilcove, D.S. and Oppenheimer, M. (2010b) Climate change increases risk of plant invasion in the Eastern United States. Biological Invasions 12, 1855-1872.

Bradley, B.A., Blumenthal, D.M., Early, R., Grosholz, E.D., Lawler, J.J., Miller, L.P., Sorte, C.J.B., D’Antonio, C.M., Diez, J.M., Dukes, J.S., Ibanez, I. and Olden, J.D. (2012) Global change, global trade, and the next wave of plant invasions. Frontiers in Ecology and the Environment 10, 20-28.

Bridges, D.C. (1992) Crop Losses Due to Weeds in the United States, 1992. Weed Science Society of America, Champaign, Illinois.

Broennimann, O., Treier, U.A., Muller-Scharer, H., Thuiller, W., Peterson, A.T. and Guisan, A. (2007) Evidence of climatic niche shift during biological invasion. Ecology Letters 10, 701-709.

Brooks, M.L., D'Antonio, C.M., Richardson, D.M., Grace, J.B., Keeley, J.E., Ditomaso, J.M., Hobbs, R.J., Pellant, M. and Pyke, D. (2004) Effects of invasive alien plants on fire regimes. Bioscience 54, 677-688.

D'Antonio, C.M. and Vitousek, P.M. (1992) Biological invasions by exotic grasses, the grass fire cycle, and global change. Annual Review of Ecology and Systematics 23, 63-87.

Dormann, C.F. (2007) Promising the future? Global change projections of species distributions. Basic and Applied Ecology 8, 387-397.

Elith, J., et al. (2006) Novel methods improve prediction of species' distributions from occurrence data. Ecography 29, 129-151.

Elith, J., Kearney, M. and Phillips, S. (2010) The art of modelling range-shifting species. Methods in Ecology and Evolution 1, 330-342.

Estes, L.D., Bradley, B.A., Beukes, H., Hole, D.G., Lau, M., Oppenheimer, M., Schulze, R., Tadross, M.A. and Turner, W.R. (2013) Comparing mechanistic and empirical model projections of crop suitability and productivity: implications for ecological forecasting. Global Ecology and Biogeography 22, 1007-1018.

Farber, O. and Kadmon, R. (2003) Assessment of alternative approaches for bioclimatic modeling with special emphasis on the Mahalanobis distance. Ecological Modelling 160, 115-130.

Franklin, J. (2009) Mapping Species Distributions: Spatial Inference and Prediction. Cambridge University Press, Cambridge, UK.

Guisan, A. and Zimmermann, N.E. (2000) Predictive habitat distribution models in ecology. Ecological Modelling 135, 147-186. 
Harris, J.A., Hobbs, R.J., Higgs, E. and Aronson, J. (2006) Ecological restoration and global climate change. Restoration Ecology 14, 170-176.

Hijmans, R.J. and Graham, C.H. (2006) The ability of climate envelope models to predict the effect of climate change on species distributions. Global Change Biology 12, 2272-2281.

Holcombe, T.R., Stohlgren, T.J. and Jarnevich, C.S. (2010) From points to forecasts: predicting invasive species habitat suitability in the near term. Diversity 2, 738-767.

Hulme, P.E. (2006) Beyond control: wider implications for the management of biological invasions. Journal of Applied Ecology 43, 835847.

Hulme, P.E. (2009) Trade, transport and trouble: managing invasive species pathways in an era of globalization. Journal of Applied Ecology 46, 10-18.

Jiménez-Valverde, A., Lobo, J.M. and Hortal, J. (2008) Not as good as they seem: the importance of concepts in species distribution modelling. Diversity and Distributions 14, 885-890.

Jiménez-Valverde, A., Diniz, F., De Azevedo, E.B. and Borges, P.A.V. (2009) Species distribution models do not account for abundance: the case of arthropods on Terceira Island. Annales Zoologici Fennici 46, 451-464.

Knapp, P.A. (1996) Cheatgrass (Bromus tectorum L.) dominance in the Great Basin Desert history, persistence, and influences to human activities. Global Environmental Change: Human and Policy Dimensions 6, 37-52.

Kremen, C., et al. (2008) Aligning conservation priorities across taxa in Madagascar with highresolution planning tools. Science 320, 222-226.

Kulhanek, S.A., Leung, B. and Ricciardi, A. (2011) Using ecological niche models to predict the abundance and impact of invasive species: application to the common carp. Ecological Applications 21, 203-213.

Lobo, J.M., Jiménez-Valverde, A. and Hortal, J. (2010) The uncertain nature of absences and their importance in species distribution modelling. Ecography 33, 103-114.

Lockwood, J., Hoopes, M. and Marchetti, M. (2007) Invasion Ecology. Blackwell Publishing, Malden, Massachusetts, USA.

McDonald, A., Riha, S., Ditommaso, A. and Degaetano, A. (2009) Climate change and the geography of weed damage: analysis of US maize systems suggests the potential for significant range transformations. Agriculture Ecosystems and Environment 130, 131-140.

Mack, R.N. (1981) Invasions of Bromus tectorum L. into Western North America: an ecological chronicle. Agro-Ecosystems 7, 145-165.
Mack, R.N. and Erneberg, M. (2002) The United States naturalized flora: largely the product of deliberate introductions. Annals of the Missouri Botanical Garden 89, 176-189.

McLachlan, J.S., Hellmann, J.J. and Schwartz, M.W. (2007) A framework for debate of assisted migration in an era of climate change. Conservation Biology 21, 297-302.

Marvin, D.C., Bradley, B.A. and Wilcove, D.S. (2009) A novel, web-based ecosystem mapping tool using expert opinion. Natural Areas Journal 29, 281-292.

Moody, M.E. and Mack, R.N. (1988) Controlling the spread of plant invasions - the importance of nascent foci. Journal of Applied Ecology 25, 1009-1021.

Nielsen, S.E., Johnson, C.J., Heard, D.C. and Boyce, M.S. (2005) Can models of presenceabsence be used to scale abundance? - Two case studies considering extremes in life history. Ecography 28, 197-208.

O’Donnell, J., Gallagher, R.V., Wilson, P.D., Downey, P.O., Hughes, L. and Leishman, M.R. (2012) Invasion hotspots for non-native plants in Australia under current and future climates. Global Change Biology 18, 617-629.

Parker, I.M., Simberloff, D., Lonsdale, W.M., Goodell, K., Wonham, M., Kareiva, P.M., Williamson, M.H., Von Holle, B., Moyle, P.B., Byers, J.E. and Goldwasser, L. (1999) Impact: toward a framework for understanding the ecological effects of invaders. Biological Invasions 1, 3-19.

Parker-Allie, F., Musil, C.F. and Thuiller, W. (2009) Effects of climate warming on the distributions of invasive Eurasian annual grasses: a South African perspective. Climatic Change 94, 87-103.

Parmesan, C. and Yohe, G. (2003) A globally coherent fingerprint of climate change impacts across natural systems. Nature 421, 37-42.

Pearce, J. and Ferrier, S. (2001) The practical value of modelling relative abundance of species for regional conservation planning: a case study. Biological Conservation 98, 33-43.

Pearson, R.G. and Dawson, T.P. (2003) Predicting the impacts of climate change on the distribution of species: are bioclimate envelope models useful? Global Ecology and Biogeography 12, 361-371.

Phillips, S.J., Anderson, R.P. and Schapire, R.E. (2006) Maximum entropy modeling of species geographic distributions. Ecological Modelling 190, 231-259.

Pysek, P. and Richardson, D.M. (2007) Traits associated with invasiveness in alien plants: Where do we stand? In: Nentwig, W. (ed.) 
Biological Invasion, Ecological Studies. Springer-Verlag, Berlin and Heidelberg, pp. 97-126.

Reichard, S.H. and White, P. (2001) Horticulture as a pathway of invasive plant introductions in the United States. Bioscience 51, 103-113.

Richardson, D.M., et al. (2009) Multidimensional evaluation of managed relocation. Proceedings of the National Academy of Sciences 106, 9721-9724.

Root, T.L., Price, J.T., Hall, K.R., Schneider, S.H., Rosenzweig, C. and Pounds, J.A. (2003) Fingerprints of global warming on wild animals and plants. Nature 421, 57-60.

Stohlgren, T.J. and Schnase, J.L. (2006) Risk analysis for biological hazards: What we need to know about invasive species. Risk Analysis 26, 163-173.

Stohlgren, T., et al. (2011) Widespread plant species: natives versus aliens in our changing world. Biological Invasions 13, 1931-1944.

Strayer, D.L. (2009) Twenty years of zebra mussels: lessons from the mollusk that made headlines. Frontiers in Ecology and the Environment 7, 135-141.

Thomas, C.D., et al. (2004) Extinction risk from climate change. Nature 427, 145-148.

Tôrres, N.M., De Marco, P., Santos, T., Silveira, L., De Almeida Jácomo, A.T. and Diniz-Filho, J.A.F. (2012) Can species distribution modelling provide estimates of population densities? A case study with jaguars in the Neotropics. Diversity and Distributions 18, 615-627.

Tsoar, A., Allouche, O., Steinitz, O., Rotem, D. and Kadmon, R. (2007) A comparative evaluation of presence-only methods for modelling species distribution. Diversity and Distributions 13, 397405.

USDA-NRCS (2012) The PLANTS Database (http:// plants.usda.gov). National Plant Data Center, Baton Rouge, Lousiana.

Václavík, T. and Meentemeyer, R.K. (2012) Equilibrium or not? Modelling potential distribution of invasive species in different stages of invasion. Diversity and Distributions 18, 73-83.

VanDerWal, J., Shoo, L.P., Graham, C. and Williams, S.E. (2009a) Selecting pseudo-absence data for presence-only distribution modeling: How far should you stray from what you know? Ecological Modelling 220, 589-594.

VanDerWal, J., Shoo, L.P., Johnson, C.N. and Williams, S.E. (2009b) Abundance and the environmental niche: environmental suitability estimated from niche models predicts the upper limit of local abundance. American Naturalist 174, 282-291.

Vila, M. and Pujadas, J. (2001) Land-use and socioeconomic correlates of plant invasions in European and North African countries. Biological Conservation 100, 397-401.

Welk, E. (2004) Constraints in range predictions of invasive plant species due to non-equilibrium distribution patterns: purple loosestrife (Lythrum salicaria) in North America. Ecological Modelling 179, 551-567.

Williams, J.W. and Jackson, S.T. (2007) Novel climates, no-analog communities, and ecological surprises. Frontiers in Ecology and the Environment 5, 475-482. 